\title{
As bandas de congo mirins: ensino popular e vivência de cultura afro-brasileira na Serra (ES)
}

\author{
The Congo children groups: popular education \\ and experience of Afro-Brazilian culture in Serra (ES)
}

Michel Dal Col Costa*

\section{RESUMO}

$\mathrm{O}$ artigo busca apresentar um pouco da tradição das bandas de congo da cidade da Serra, na Região Metropolitana de Vitória (ES), focalizando especialmente a história da participação das crianças nessas manifestações culturais. Com base em um retrato dessa participação ao longo dos tempos, constituído por observação etnográfica, entrevistas e outras fontes, pretende-se entender melhor o trabalho estruturado feito com as crianças nas chamadas "bandas de congo mirins" da região. Apontam-se alguns elementos do processo de transmissão cultural de conhecimentos referentes a essa cultura e mostra-se como tais elementos ainda se valem de formas antigas e tradicionais de ensino da cultura presentes nessas comunidades. Com isso, apresenta-se a face popular de um ensino não escolar e a vivência da cultura afro-brasileira em um município brasileiro.

Palavras-chave: transmissão cultural; banda de congo; crianças.

\section{Abstract}

The article seeks to present a little of the tradition of Serra Congo groups, in the Metropolitan Region of Vitória (ES), focusing mainly on the history of the participation of children in these cultural events. The intention is, from a portrait of this participation over the course of time, made up from the ethnographic observation, interviews and other sources, understand better the work structured done with children in the so-called "children Congo groups" of the region. I will point out some elements of the process of cultural transmission of knowledge related to this culture, and show how they are still worth of old forms and traditional teaching of culture in these communities. With this, I seek to present a popular face of an education non-school and experience of the Afro-Brazilian culture in a Brazilian city. Keywords: cultural transmission; Congo groups; children.

\footnotetext{
* Mestrando em História Social das Relações Políticas. Universidade Federal do Espírito Santo (Ufes), Programa de Pós-Graduação em História. Av. Fernando Ferrari, 514 - Campus de Goiabeiras.29075-910 Vitória - ES - Brasil. micheldalcolcosta2@gmail.com
} 
Nos últimos anos, na cidade da Serra, no estado do Espírito Santo, tem ocorrido uma experiência bem-sucedida de ensino de elementos culturais afro-capixabas-brasileiros. Não se trata de uma atuação de técnicos educacionais ou professores formados nas universidades, mas de uma ação realizada, em geral, por indivíduos de outra formação: os chamados 'mestres do folclore'. Trata-se dos líderes das bandas de congo locais que, depois de um período de atuação autônoma, recebem apoio da administração municipal para desenvolver o projeto das bandas de congo mirins, as quais envolvem as crianças de várias comunidades nessa que é uma das mais importantes manifestações do universo da identidade cultural capixaba.

É um projeto que se aproxima das diretrizes indicadas na Carta do Folclore Brasileiro, aprovada em 1951, no I Congresso Brasileiro de Folclore, que preconizava a utilização de elementos do folclore na educação, não apenas como conteúdos, mas como elementos para serem vivenciados. ${ }^{1} \mathrm{Um}$ recurso que tem sido utilizado por muitos professores que buscam realizar aulas significativas do ponto de vista da dinâmica do aprendizado e também por grupos chamados parafolclóricos, que buscam reproduzir as culturas tradicionais.

Este artigo, portanto, tratará de um processo de transmissão cultural em execução nas comunidades congueiras do Espírito Santo, tendo como foco a cidade da Serra, que é um dos municípios da Região Metropolitana de Vitória. Os processos de transmissão cultural estão imbricados na essência do conceito de cultura como será utilizado aqui, segundo a definição de Darcy Ribeiro em seus Estudos de Antropologia da Civilização:

Cultura é a herança social de uma comunidade humana, representada pelo acervo coparticipado de modos padronizados de adaptação à natureza para o provimento de subsistência, de normas e instituições reguladoras das relações sociais e de corpos de saber, de valores e de crenças com que seus membros explicam sua experiência, exprimem sua criatividade artística e a motivam para a ação ... é uma ordem particular de fenômenos que tem de característico sua natureza de réplica conceitual da realidade, transmissível simbolicamente de geração a geração, na forma de uma tradição que provê modos de existência, formas de organização e meios de expressão a uma comunidade humana. ${ }^{2}$

O conceito de transmissão cultural, implicitamente mencionado por Darcy Ribeiro nessa passagem, tem sido utilizado por João Francisco Souza. 
Em artigo publicado na internet intitulado “A Transmissão Cultural”, esse autor o definiu como "processos socioculturais no interior de processos educativos não escolares ou de uma escola pública". ${ }^{3}$ Para João F. Souza, tendo como base Otávio Ianni, esses processos teriam dimensões que o configuram como socialização ou como espaços educativos, geradores de uma identidade cultural, pessoal e comunitária, para além da identidade nacional. Seria um movimento educativo que trabalha com a tradição humana ou, com base em Henri Giroux, uma política cultural (Souza, 2009).

Inés Dussel, também trabalhando com a realidade das transmissões culturais, apontou que vivemos na atualidade uma crise da transmissão cultural na sociedade. A autora afirma que essa crise se manifesta nas escolas, lócus clássico da transmissão cultural, e pode ser expressa a partir da noção de 'liquidez’ de Zygmunt Bauman. Nessa perspectiva, as formas duradouras e estáveis perderam prestígio em um mundo pautado pelo individualismo capitalista. A liquidez cultural existente traz dificuldades para "estabelecer laços coletivos, formas de autoridade tradicionais e pautas de transmissão cultural mais estáveis e duradouras". ${ }^{4}$

Fundamentada em Laura Malosetti Costa, Inés Dussel frisa que, para a vivência de uma transmissão cultural efetiva com base em uma cultura comum e que dê sustentação para sair do individualismo e liquidez atual, é importante se ter uma relação mais livre com uma tradição. Nessa liberdade, por exemplo, deve haver um lugar para que a tradição possa ser reescrita. Isto é, a transmissão cultural, ou 'reprodução cultural' (como denominou Pierre Bourdieu), deve ser algo que se aproximaria da definição dada por Peter Burke, "um processo de criação contínua". ${ }^{5}$

Penso que a problemática da transmissão cultural da herança material e imaterial das sociedades na atualidade serve como referencial teórico oportuno para pensarmos a experiência da formação das bandas de congo mirins do Espírito Santo, uma prática educacional popular não escolar. Neste texto será apresentada uma experiência de transmissão cultural que é um esforço afirmativo de preservação e reprodução de elementos culturais tradicionais no contexto atual. Em um primeiro momento, resumiremos aspectos fundamentais da cultura das bandas de congo capixabas e seus universos de vida. Depois, acompanharemos a evolução da participação e aprendizado das crianças nessas comunidades tradicionais. E por fim, serão apresentados elementos do 
processo de transmissão cultural presentes na experiência das bandas de congo mirins. O foco espacial principal será sempre a cidade da Serra, contudo, serão feitas algumas poucas referências a outras cidades do Espírito Santo, uma vez que a cultura do congo pertence a vários municípios do Estado.

Mas, para visualizarmos melhor essa história, imagino que será de grande valia conhecer um pouco sobre as bandas de congo capixabas e seus universos de vida e também acompanharmos a evolução da participação e do aprendizado das crianças nessas comunidades tradicionais.

\section{As BANDAS DE CONGO E SEU CICLO FOLCLÓRICO E RELIGIOSO}

As bandas de congo são grupos musicais de percussão, coro de vozes e dança. Elas existem na Região Metropolitana de Vitória (ES), chegando até seu interior, nas cidades de Anchieta, Ibiraçu e Colatina, dentre outras. ${ }^{6}$ Podemos dizer que há uma 'área cultural' ${ }^{7}$ das bandas de congo no Espírito Santo. A sua origem remete aos africanos e indígenas e à influência dos colonizadores portugueses, mas a origem temporal é difícil de determinar com exatidão. ${ }^{8}$

A parte da percussão é muito rica e variada. Os grupos são formados por vários homens tocando tambores com as mãos, sendo utilizadas baquetas somente pelos tocadores de bumbo e de caixa. Esses tambores são diversificados, pois existem os de marcação ou de base e os de repique. Há ainda um instrumento denominado 'cuíca', que, ao que parece, é uma forma rústica e primitiva das modernas cuícas utilizadas no samba. O chocalho e o triângulo também são usados. No conjunto, todos esses instrumentos geram um efeito muito interessante.

Um instrumento que merece destaque especial é a chamada 'casaca' ou 'reco-reco', ${ }^{9}$ sua denominação mais usual em todo o mundo. Toca-se a casaca raspando os seus dentes feitos de bambu com uma varinha. A casaca possui uma cabeça humana esculpida na extremidade superior. São vários os tocadores de casaca, que, com os outros instrumentos, produzem uma sonoridade muito interessante e rica. ${ }^{10}$

As canções trazem expressões de inúmeros temas referentes à realidade e à natureza locais: canções de amor à mulher e sobre a vida cotidiana da comunidade e da família; assuntos referentes às próprias bandas de congo e sua função; temas do passado das comunidades onde estão os grupos; e, acima de 
tudo, temas de louvor, agradecimento e honra aos santos da Igreja aos quais rendem homenagens. A homenagem aparece também nos estandartes de cada grupo, podendo haver estandartes de dois santos, ou mais, na mesma banda. ${ }^{11}$

$\mathrm{Na}$ cidade da Serra essa cultura é muito forte, e é essa a área cultural que possui o maior número de grupos em todo o Espírito Santo. Em sua grande maioria, esses grupos são organizados e administrados pelas suas comunidades e pela Associação das Bandas de Congo da Serra (ABC-Serra). Fundada em 1986, é uma entidade criada para organizar, proteger e fortalecer os grupos e lutar por seus direitos dentro da municipalidade, junto à sociedade e ao Poder Público. ${ }^{12}$

Citemos algumas das inúmeras denominações de bandas de congo do município da Serra: Banda de Congo de Nossa Senhora da Conceição, de Jacaraípe; Banda de Congo de São Benedito e Nossa Senhora do Rosário, do bairro Pitanga; Banda de Congo de São Sebastião e São Benedito, de Nova Almeida; Banda de Congo de São Benedito, de Santiago; Banda de Congo Folclórico de São Benedito, do Bairro São Domingos, na região da Serra Sede; Banda de Congo de Santo Expedito, também do Bairro São Domingos; Banda de Congo Konshaça, de Serra Sede; e Banda de Congo São Benedito, do bairro Campinho da Serra.

Uma das festas da Serra Sede, a de São Benedito, é tida como a mais importante, e ocorre no mínimo desde meados do século XVIII, ${ }^{13}$ sendo considerada uma das maiores festas dedicadas a São Benedito no Espírito Santo. Em seu ritual há, em resumo, um cortejo festivo que percorre as ruas do Centro da Serra, nas proximidades da Igreja Matriz, com a finalidade de celebrar São Benedito, culminando com a fincada de um mastro com a bandeira do santo em frente ao templo.

Ocorre um ritual em torno desse mastro. No início da preparação dos festejos, o mastro é cortado pelo povo, capitaneado por Mestre Expedito, ${ }^{14} \mathrm{da}$ Banda de Congo de Santo Expedito, de São Domingos. Depois, essa madeira, ainda verde, ${ }^{15}$ é puxada simbolicamente por uma junta de bois, que são enfeitados e acompanhados por um cortejo do povo e de cavaleiros. ${ }^{16}$ Trata-se de um cortejo preparatório para o que ocorre nos dias 25 e 26 de dezembro, quando o mastro, já preparado, é posto dentro de um navio com rodas e puxado pelas ruas da cidade, até ser fincado no dia dedicado a São Benedito, 26 de dezembro. Esse ciclo anual do ritual, portanto, se inicia com o corte da 
madeira na mata e é fechado com a Celebração da Retirada do Mastro, meses depois de ter ficado exposto em frente à Igreja Matriz, no domingo da Páscoa.

Este pequeno resumo da Festa de São Benedito da Serra Sede mostra um pouco do principal palco no qual se apresentam as bandas de congo. O povo realiza esse ritual há mais de um século, como devoção e cumprimento de promessas pessoais a São Benedito e em agradecimento por um milagre que o santo negro teria operado no litoral de Nova Almeida, ao salvar um grupo de escravos de um naufrágio, como conta a explicação tradicional e popular da origem dessa festa folclórica. ${ }^{17}$

Há festas semelhantes em inúmeras outras localidades do município da Serra em que as bandas de congo são presença marcante, como Santiago, Pitanga, Manguinhos, Jacaraípe e Nova Almeida, e também em outras cidades da Grande Vitória e do interior. Todas são dedicadas aos santos da Igreja Católica, como Nossa Senhora do Rosário, que em Pitanga é celebrada em outubro, junto a São Benedito; São Pedro, em Jacaraípe, e Santana e São Sebastião, em Manguinhos. São Sebastião também é celebrado em Nova Almeida e Santiago, junto a São Benedito (Costa, 2008-2011).

Todo esse conjunto de festas parte de um mesmo conceito ritualístico, compondo o "Ciclo Folclórico e Religioso da Serra", como se costuma denominar o complexo dos rituais das bandas de congo do município (Costa, 2010).

Basicamente, esse relato é a herança cultural vivida no processo sociocultural de transmissão cultural operado na formação das bandas de congo mirins do município da Serra e também em outros espaços educacionais. Mas esse processo de ensino não escolar de uma cultura afro-capixaba-brasileira que tem sido estruturado no projeto das bandas mirins na atualidade já existia anteriormente, mediante formas tradicionais de transmissão de conhecimento e de participação das crianças nessas práticas. Assuntos de que trataremos nas seções seguintes.

\section{PROCESSO HISTÓRICO DE PARTICIPAÇÃO \\ DAS CRIANÇAS NAS bandas de CONGo Da SERRa}

É antigo o caminho de trabalho ou de envolvimento das crianças cantando, dançando e tendo contato com os instrumentos nos grupos de congo no município da Serra. E isso certamente remonta aos primórdios desses grupos, 
na época colonial. A forma cultural das bandas de congo, no caso, é mais antiga que os rituais da fincada do mastro, descrito resumidamente linhas atrás, que surgiu já no século XIX, depois da independência do Brasil. Podemos periodizar a participação das crianças em várias fases da trajetória histórica desses grupos na cidade.

A primeira fase da história desses grupos pode ser chamada de 'espontânea'. Acredito ser talvez a mais longa de todas as etapas, já que algumas de suas características perduram até a realidade atual, quando vivemos outro momento histórico. Recebe a denominação de 'tempo de participação espontânea' porque remonta a um momento em que ainda não havia estruturas organizadas de ensino, entendidas como papéis específicos dentro das comunidades para esse trabalho. Hoje, o trabalho com as crianças nas bandas de congo está estruturado com base na Associação de Bandas de Congo (ABC-Serra), graças a uma lei municipal que a regulamenta, e envolve os coordenadores dos grupos, instrumentos e indumentárias próprias para as crianças, grupos mirins oficiais etc. Enfim, há toda uma estrutura de aprendizado e de vida direcionada para as crianças, que não existia no período histórico que se denomina primeira fase, 'espontânea'.

Podemos dizer que, na fase espontânea, aos pais, mães, parentes e membros sábios da comunidade cabiam as relações de ensino com as crianças, e isso certamente acontecia muito mais por meio do processo de imitação e participação livre nos momentos em que os adultos estavam vivenciando a prática cultural. ${ }^{18}$

O trabalho com as crianças nessa fase primeira estaria relacionado com ligações familiares e apegos a determinado aspecto cultural. Para entender o processo de relação das crianças com a cultura da música das bandas de congo é preciso ter como pano de fundo as formas antigas de transmissão cultural adotadas pelas tribos indígenas e pelas próprias tribos africanas, que foram as construtoras dessa arte. Esta é uma hipótese inferida da história desses grupos. $\mathrm{Na}$ atualidade, as coisas andam de forma diferente, mas evidentemente com permanências dessa primeira fase.

Temos notícias, graças à história oral, de que na década de 1940 ocorreu na Serra um momento histórico importante: a experiência da Banda de Congo de Antônio Rosa, formada por garotos e amigos, o chamado "Conguinho". Desse grupo participou Mestre Victor Sacramento, muito antes de se tornar 
mestre e entrar na Banda de Congo Folclórico São Benedito, importante grupo da Serra. ${ }^{19}$ Podemos denominá-la de fase 'espontânea organizada', pois, segundo consta, foi uma iniciativa dos próprios jovens, e de uma forma minimamente organizada, como ficou na memória dos entrevistados.

Nessa época, as crianças participaram como agentes específicos, mas de forma localizada, sem um projeto mais amplo como temos na atualidade. Hoje, há um projeto integrado entre a Associação das Bandas de Congo da Serra, a Prefeitura Municipal e as comunidades das bandas de congo, envolvendo toda a cidade. O período histórico que unia a espontaneidade da primeira fase e princípios iniciais de organização marcou um novo momento histórico, quando o grupo de meninos do pequeno meio urbano da Serra se reuniu e formou uma banda de congo para sair tocando pelo povoado, como um tipo de imitação das bandas adultas.

Eles só podiam fazê-lo porque foram capazes de organizar o conhecimento proveniente de suas percepções e experiências dentro dessa cultura da Serra e o aplicaram. Arrumaram meios de construir os instrumentos e fizeram esses grupos, ao que parece, sem acompanhamento adulto. Uma informante disse que esse grupo foi formado pelo antigo festeiro da cidade, o senhor João Rosa Machado, pai de Antônio Rosa, na época um dos jovens congueiros, mas isso não foi mencionado pelos demais entrevistados.

A terceira fase histórica da participação das crianças na cultura das bandas de congo pode ser denominada de fase 'organizada de projetos-piloto'. Nela, ocorrem iniciativas que buscaram viver o ensino da cultura das bandas de congo de modo fragmentado, ao sabor das vontades e iniciativas culturais de alguns mestres de congo locais, preocupados com o futuro dessas manifestações folclóricas. Dentre esses professores de congo, podemos citar o Mestre Vacinto Rosário Bento, o Zé Bento de Nova Almeida, e o professor José Carlos de Miranda Filho, o Zé Carlos da Banda Konshaça, de Serra Sede. Este último foi o que podemos chamar de precursor, com a banda que formou para participar da parada militar anual na Serra, no início da década de 1980. Segundo Zé Carlos, essa banda foi formada por um conjunto de instrumentos que ele construiu para o evento, que emocionou a todos com a encenação da Festa de São Benedito da Serra em plena "Parada das Escolas". Zé Carlos ainda chegou a montar, na década de 1980, a banda mirim do Bairro Santo Antônio, que não foi adiante, mas recentemente foi reativada. ${ }^{20}$ 
O trabalho do professor Zé Carlos continua na atualidade. Ele está coordenando o Projeto Congo na Escola, com grupos formados na Escola Serrana e na Escola Municipal de Educação Infantil "Mônica", ambas na Serra Sede (Figura 1). Os grupos se apresentam nas escolas, possuem indumentária especial e instrumentos próprios.

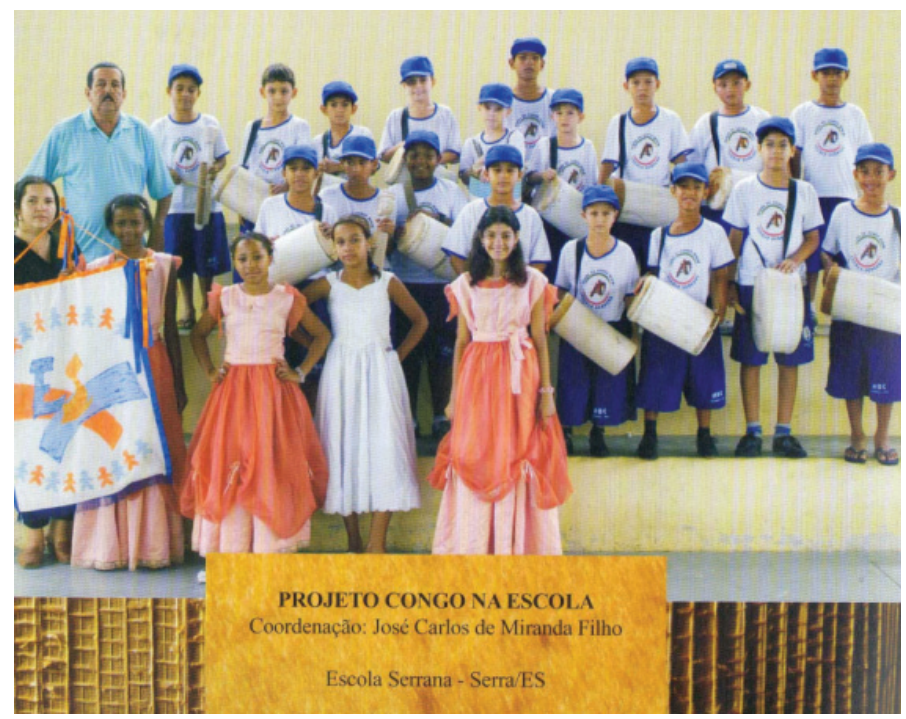

Figura 1 - Projeto Congo na Escola. No alto, à esquerda, o professor Zé Carlos. Fonte: CD das Bandas de Congo da Serra: "Congo. O Canto da Alma. Volume 2". Foto: Edson Reis.

Já o Mestre Zé Bento montou um projeto inovador por volta de 1984, que até hoje dá seus frutos. Ele o executou com o aval de Mestre Antônio Rosa, ${ }^{21}$ que, na época, o havia sondado para a formação de mais uma banda em Nova Almeida. Zé Bento prontamente aceitou, mas com a condição de que realizaria um trabalho com as crianças da comunidade. Disse que seria interessante realizar tal trabalho, pois estariam pensando no futuro da tradição, formando congueiros para conduzir a cultura no futuro. Mestre Antônio Rosa entendeu que seria interessante e bom. Com isso, Zé Bento formou a "Banda de Congo União Jovens dos Reis Magos”. Esse projeto está operante até hoje e já formou vários congueiros adultos e grupos juvenis. 
Zé Bento ainda trabalhou nessa área com crianças no Projeto Gaivotas de Nova Almeida -Serra (Figura 2) e com crianças carentes no Bairro São Pedro, em Vitória. ${ }^{22}$

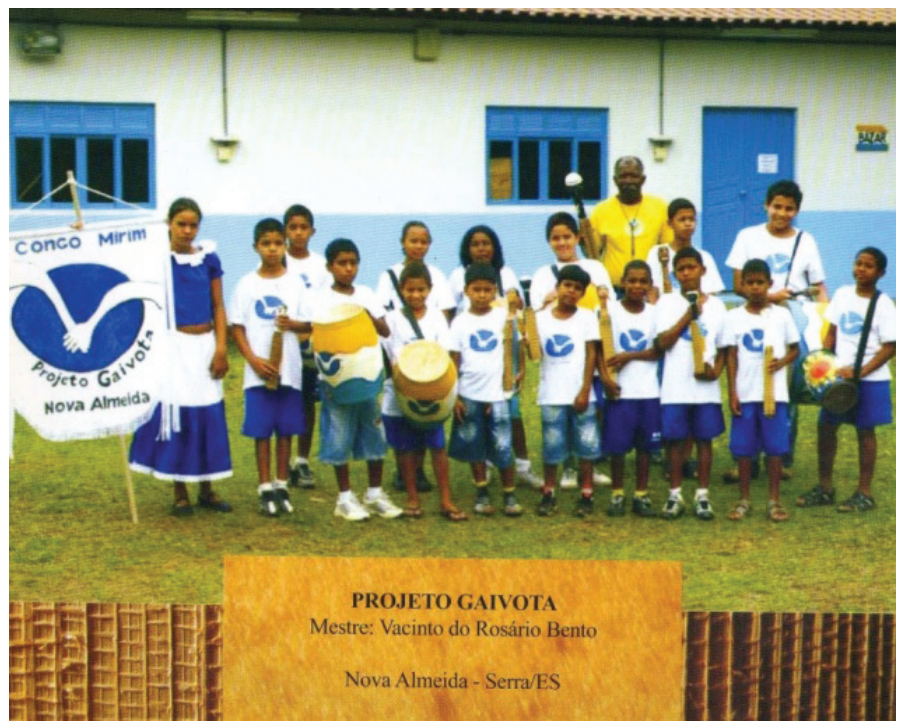

Figura 2 - Projeto Gaivota. Ao fundo, Mestre Zé Bento. Fonte: CD das Bandas de Congo da Serra: "Congo. O Canto da Alma. Volume 2". Foto: Edson Reis.

A partir do final da década de 1990 surgiu uma nova fase histórica, que chamarei aqui de 'estruturada'. Foram constituídos papéis estruturais específicos, como por exemplo a figura dos coordenadores das bandas mirins, que deram impulso aos novos trabalhos dos mestres das bandas de congo adultas. Constituíram, assim, relações novas no interior das comunidades, inserindo-as em situações e possibilidades nos campos da tradição, da arte de seus ancestrais e em sua história. Podemos dizer que a reprodução da cultura das bandas de congo, através da passagem do conhecimento entre as gerações, ganhou um impulso fenomenal.

A grande responsável pela realização do projeto das bandas mirins da atualidade junto às crianças da Serra é a Associação das Bandas de Congo (ABC-Serra). A entidade firmou parceria histórica com a Prefeitura Municipal no alvorecer do novo milênio, quando se estabeleceu que as bandas de congo 
da Serra receberiam um benefício financeiro, com a contrapartida de realizarem um trabalho estruturado junto às crianças da comunidade e formarem grupos de crianças aprendizes como parte de suas bandas. Outra contrapartida seria o fato de os meninos e as meninas serem devidamente matriculados no ensino regular. ${ }^{23}$

Temos, portanto, segundo nosso modo de interpretar, quatro fases da história das crianças nas bandas de congo da Serra: fase espontânea (dos primórdios no período colonial até a década de 1940); fase espontânea organizada (década de 1940 até o início da década de 1980); fase dos projetos estruturados pilotos (décadas de 1980 e 1990), e a fase estruturada (final da década de 1990 até a atualidade). Todas as fases são importantes e foram se organizando ao longo da história até chegar à atual, mantendo muitos elementos das fases antigas.

O ensino que se observa na fase estruturada da atualidade vale-se, na prática, das experiências acumuladas ao longo dos anos, da força dos ambientes familiares dos congueiros, das relações de amizade e das comunitárias próximas, entre outros fatores. E quem em geral organiza, ensina e realiza o projeto das bandas mirins são os mestres das diversas bandas de congo. E esses mestres, na sua história de vida, participaram de formas de ensino antigas e tradicionais de suas comunidades. Com isso, eles utilizam na sua atuação, práticas de ensino que foram importantes em suas próprias trajetórias.

É interessante mencionar que a cidade da Serra, bem como a Região Metropolitana da Grande Vitória como um todo, a partir da década de 1970 passou por transformações tremendas em sua realidade. O município que até essa década tinha menos de 20 mil habitantes passou rapidamente ao montante de mais de 400 mil, como se contabilizou no censo de 2010 do IBGE. Isso se deve ao processo de industrialização iniciado na década de 1970, que mudou a realidade de uma cidade basicamente ligada às atividades rurais, tornando-a um dos maiores centros migratórios do Espírito Santo. Vieram famílias de Minas Gerais, da Bahia e de outras regiões do Brasil, ou seja, pessoas que não tinha ligações com a cultura tradicional da cidade. Foi nesse contexto que, na década de 1980, quando começaram muitos loteamentos regulares e irregulares e apareceu o fenômeno da favelização, os problemas sociais se tornaram marcantes e surgiram as primeiras iniciativas de trabalho com as crianças no sentido de preservação da cultura tradicional das bandas de congo. Essas ini- 
ciativas piloto foram sendo aperfeiçoadas até chegarem à fase estruturada que está sendo vivenciada efetivamente desde o ano 2000.

\section{BANDAS MIRINS}

As crianças são inscritas nos projetos das diversas bandas de congo tradicionais adultas da cidade da Serra. Geralmente são coordenadas pelos mestres dos grupos adultos, com a coparticipação de coordenadores específicos escolhidos nas comunidades para cuidar do aprendizado, dos encontros de ensaio e das apresentações.

Nos encontros previamente marcados se ensinam elementos básicos das bandas de congo, de acordo com os costumes de cada comunidade. As crianças aprendem as letras das canções tradicionais e as melodias, apesar de, pela própria experiência, poderem já ter tido algum contato com as toadas tocadas pelos grupos adultos. Aprendem a história do congo e suas tradições e adquirem conhecimentos sobre o instrumental.

Cada congueirinho, com idade entre 3 e 14 anos, passa por uma avaliação, para saber qual instrumento vai tocar. Os mais desenvoltos, que aprendem a tocar vários instrumentos, aprendem também a função de mestre ou capitão do grupo e ficam incumbidos de governar o conjunto, organizando os instrumentistas para que todos toquem dentro do ritmo, cadência e entonação correta. Em geral, esses pequenos mestres utilizam um apito (como os grupos adultos) para auxiliar na organização da orquestra de percussão e das vozes em coro, que são a marca da música das bandas de congo.

Passam o ano se encontrando para conversar, aprender e ensaiar, preparando as diversas apresentações que fazem em eventos e escolas, apresentações estas para as quais são encaminhados pelos seus coordenadores e pela própria ABC-Serra. Os pontos altos de suas apresentações são os Encontros de Bandas de Congo Mirins da Serra e o de Nova Almeida, bairro da cidade. O primeiro ocorre todo dezembro nas ruas da Serra Sede; o segundo é realizado em janeiro, nas imediações da Igreja Jesuítica dos Reis Magos. ${ }^{24}$ Esses encontros não possuem data fixa e já se deram em vários dias desses meses. O importante é que ocorram em dezembro e janeiro, como uma das partes dos festejos de São Benedito da Serra Sede (dezembro) e de São Sebastião e São Benedito de Nova 
Almeida (janeiro). O Encontro de Bandas Mirins da Serra Sede, o mais antigo, em 2012, vai para a sua 12a edição, e o de Nova Almeida é mais novo.

Nesses encontros tudo começa por volta das 18 horas, com a chegada dos grupos em ônibus particulares. Com suas indumentárias, as crianças chegam de diversas partes da Serra e de outros municípios. Vêm de São Domingos, de Campinho da Serra, de Pitanga, de Santiago, de Manguinhos, de Jacaraípe, de Nova Almeida, de Bicanga e, em geral, do município de Fundão, que prestigia o encontro serrano com a Banda de Congo Mirim do Distrito de Timbuí e com outros grupos.

Em geral, na Serra Sede a concentração da criançada ocorre na Escola Estadual de Educação Fundamental e Média Professor João Loyola, onde salas de aula são separada para os grupos. Os momentos iniciais desse evento são muito interessantes, pois enquanto esperam o início das atividades, os membros dos grupos de congo mirim ficam se divertindo com os instrumentos no pátio da escola. É uma 'festa' em todos os corredores, nas salas e na quadra de esportes do colégio, que serve de local para brincadeiras, correrias e convivência da criançada. Todos chegam muito alegres, com batuques e cantigas, e essa alegria permanece nos momentos que antecedem as atividades do evento (ver Figura 3).

Dentre os grupos mirins da Serra, os que mais têm participado dos encontros são: Banda de Congo Mirim União Jovens dos Reis Magos, de Nova Almeida; Banda de Congo Mirim de Sant'Ana, de Manguinhos; Banda de Congo Mirim São Pedro, de Jacaraípe; Banda de Congo Mirim Santo Antônio de Pádua, de Bicanga; Banda de Congo Mirim Nossa Senhora do Rosário, de Pitanga; Banda de Congo Mirim de São Benedito e Nossa Senhora da Conceição, de Campinho da Serra II; Banda de Congo Mirim São Benedito e Santo Antônio de Pádua, do Bairro São Domingos (Figura 3); Banda de Congo Konshacinha de Santo Antônio; e Banda de Congo Mirim São Benedito, de Santiago - Serra. ${ }^{25}$ Esses grupos (como as bandas adultas mencionadas no início do artigo) e seus respectivos povoados expressam a mancha demográfica da Serra antiga, aquela que tinha menos de 20 mil habitantes até a década de 1970. Em torno dessas comunidades foram surgindo novos bairros e loteamentos, fazendo a mancha demográfica do município crescer enormemente. Os projetos das bandas mirins têm, contudo, envolvido de diversas formas 


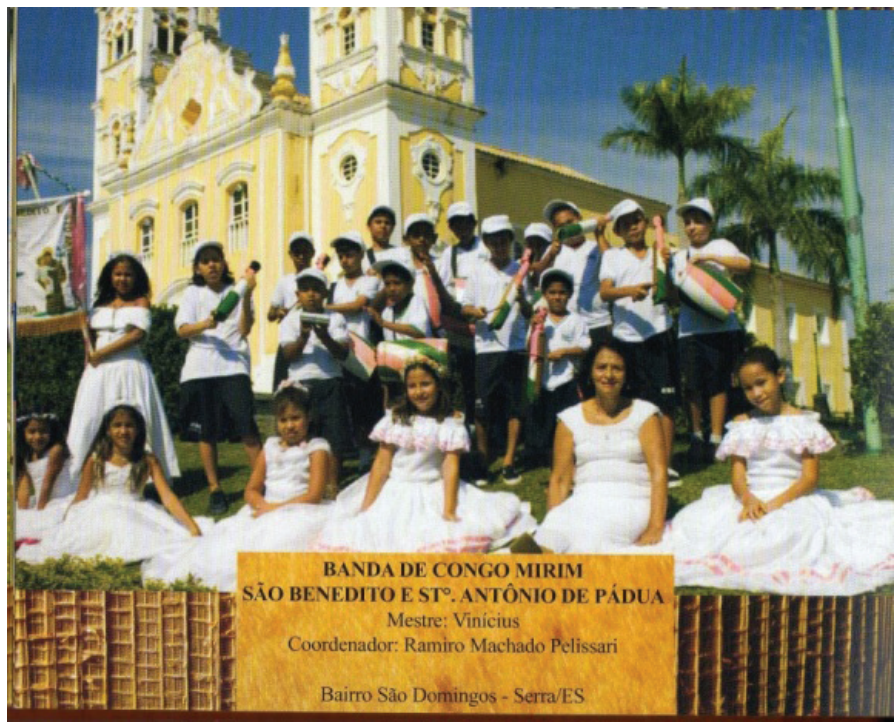

Figura 3 - A Igreja-Matriz de Nossa Senhora da Conceição da Serra, em frente da qual ocorre a Fincada do Mastro com a Bandeira de São Benedito todo dia 26 de dezembro, ao som da música das bandas de congo e da Banda Estrela dos Artistas. Em primeiro plano, como dançarina, a sra. Lolinha, viúva do festeiro Mestre Antônio Rosa, grande liderança do folclore no Espírito Santo. Fonte: CD das Bandas de Congo da Serra: "Congo. O Canto da Alma. Volume 2". Foto: Edson Reis.

pessoas ligadas ao processo migratório, e não só as pessoas vinculadas aos povoados antigos do município.

É muito interessante ver o amor, o carinho e o cuidado com que os mestres como o sr. Antônio Freitas e coordenadores como Valdirene, ambos do Bairro Santiago (Figura 4), tratam o grupo de meninos e meninas e os rituais e costumes da cultura que representam. E a criançada, até mesmo durante o lanche, fica o tempo todo tocando os instrumentos, formando pequenos grupos, com a alegria de estar realizando um trabalho coletivo, musical, orquestral, enfim, cultural. 


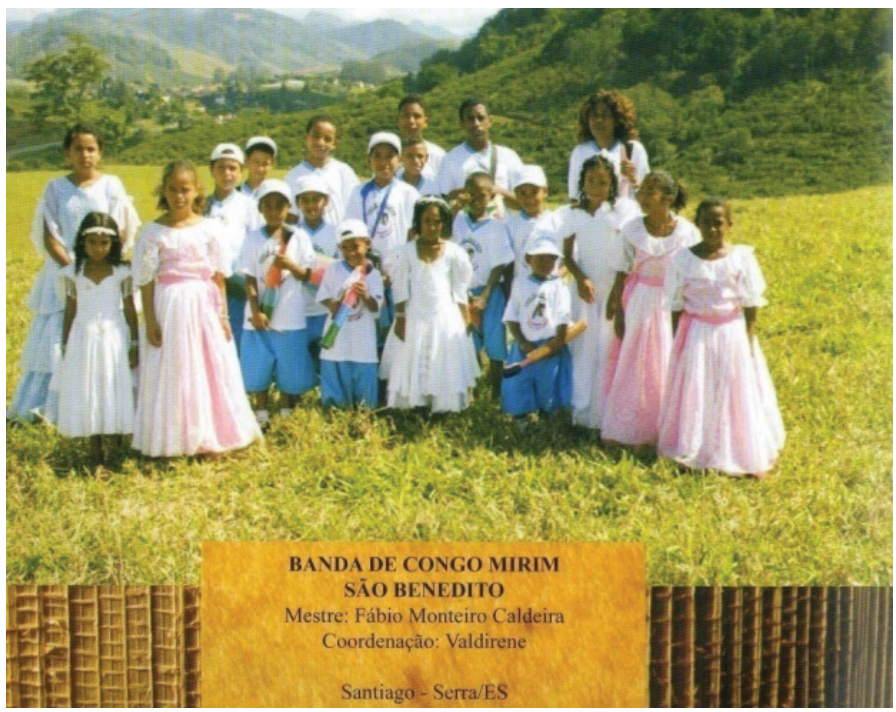

Figura 4 - Região Rural de Santiago, no limite da Serra com Fundão. À direita, ao fundo, a coordenadora e rainha da Banda de Congo São Benedito de Santiago. Atualmente ela é a presidente da ABC-Serra. Fonte: CD das Bandas de Congo da Serra: "Congo. O Canto da Alma. Volume 2". Foto: Edson Reis.

Na Serra, as apresentações dos grupos começam em um momento que precede o desfile pelas ruas principais do povoado que vai até a Igreja Matriz de Nossa Senhora da Conceição. No VIII Encontro de Bandas Mirins de 2008, todas as crianças tocaram no centro da quadra de esportes do colégio, enquanto foram apresentadas por Ramiro Pelissari, locutor do evento (coordenador da Banda Mirim São Benedito e Santo Antônio de Pádua e seu mestre do tempo da fundação). Depois disso, saem pelas ruas em fila, como no cortejo da Festa de São Benedito, porém de forma diferenciada do ritual tradicional.

Em termos indiretos, há muita ligação das bandas de congo da Serra com a vida do ritual sagrado, pois esses meninos e meninas certamente poderão, com o tempo, ser os futuros músicos das bandas de congo. É interessante mencionar que, em termos de repertório, as canções das bandas mirins, em geral, também são tocadas pelos grupos oficiais na Festa de São Benedito da Serra e nas outras festas. O que observamos é o embrião de um repertório 
próprio da festa nas bandas mirins, que aprendem nos ensaios e encontros, diferente do repertório da festa tradicional.

O repertório das cantigas é um elemento estrutural para as bandas adultas e também para o método de ensino dos mirins. Ao ensinar o ritmo e o repertório tradicional, os coordenadores e mestres dos mirins passam um conceito do que é a banda de congo e, com isso, inserem os pequenos na própria tradição das comunidades.

\section{UMA EXPERIÊNCIA DE TRANSMISSÃO CULTURAL}

No desfile das bandas mirins, as crianças são, de certa forma, iniciadas em um tipo de experiência de apresentação que se faz geralmente pelos adultos: o cortejo andando e tocando pelas ruas da cidade. Certamente muitos dos meninos já haviam passado pelo contato com essa atividade ao observarem as bandas adultas.

A experiência dos desfiles é interessante para os participantes em termos de aprendizado geral da cultura das bandas de congo, pois é um momento no qual os pequenos vivenciam a cultura, pois tocam com pessoas observando a apresentação, dançando e cantando enquanto acompanham o cortejo. E isso dá aos meninos e meninas um pouco da essência do espírito de uma apresentação pública como em geral é realizada tradicional e costumeiramente pelas bandas de congo adultas. Uma experiência como essa é primordial para dar o entendimento para os pequenos sobre a prática dessa cultura e sobre suas formas de apresentação.

Daí surge esta questão: o que é preciso para a formação de um músico de banda de congo ou de um participante geral dessa prática? Uma resposta a comunidade certamente já tem: é viver desde a infância junto aos familiares e membros da comunidade dessa cultura, treinar, aprender as músicas, viver a religiosidade, conhecê-la e se apresentar em encontros como esses, onde se reproduz o ritual dos adultos. É interessante também frisar que essa prática já revelou bons frutos em várias comunidades, pois vários mirins já foram compor as apresentações com os adultos, e muitos jovens já estão se apresentando com reconhecida competência. É o caso do próprio neto de Antônio Rosa, Ramiro, coordenador da sua antiga banda mirim e membro da Banda de Congo Folclórico São Benedito, ou dos muitos componentes da Banda Jovens em 
Prol da Cultura, que foram músicos na União Jovens dos Reis Magos de Nova Almeida. É, também, o caso da Banda Jovens de Manguinhos e da Cultura Congo de Bicanga, composta em parte por jovens músicos que cresceram acompanhando os projetos das bandas de congo mirins do Convênio ABC/ PMS, instituído em 1999. ${ }^{26}$

Um dos aspectos que pude observar nos cortejos e apresentações é que as bandas de crianças ainda não possuem a potência completa verificada na adulta ou mesmo nas de jovens, sem deixarem, no entanto, de ser animadas e alegres. Em especial no cortejo da Banda de Congo Mirim São Benedito de Santiago, algumas das crianças foram acompanhadas de perto pelos pais, por coordenadores, ou mesmo por alguns músicos mais velhos, para ajudar no acompanhamento dos instrumentos e no cantar. E esses adultos iam dando aos pequenos um apoio, pois estes se tornavam o centro das atenções. A ideia era fazê-los alcançar, naquela situação nova, da caminhada cantando, um bom nível de musicalidade. Mestre Antônio Freitas ordenava, com sua casaca, dando ritmo e firmeza aos mirins. Os mais velhos animavam os pequenos nesse sentido, com evidente respeito aos tamanhos, idades e experiências.

Houve um momento em que Valdirene, pacientemente, parou de cantar em sequência, como vinha ocorrendo, e fez os tocadores de casaca ficarem só marcando suavemente o ritmo, numa espécie de exercício de aprendizado que eles devem sempre fazer. E os tocadores dos outros instrumentos também ficaram levemente acompanhando, sem cantar nenhuma canção. E andaram assim, como se estivessem fazendo uma espécie de aquecimento e de trabalho de harmonia, para que houvesse a evolução que eles queriam desde o início.

No grupo de crianças, observa-se um núcleo mais desenvolvido em torno do mestre mirim do apito. Em torno desse grupo há outro mais jovem, que está ainda se inteirando da musicalidade do congo. Isso é dito sem o intuito de minorar o resultado coletivo da banda mirim, uma vez que o seu conjunto, sem exceção, é importante para o todo das canções em execução. Mas, ao que parece, o tocador de bumbo (que é um instrumento importantíssimo para a banda de congo, pois dá a sustentação e a base para o todo do conjunto, como vários congueiros reconhecem) tem peso preponderante no núcleo forte do grupo, para a música ecoar de forma mais solta. O tocador de bumbo, ao que parece, é fundamental no trabalho de montagem de uma banda mirim, e mesmo de uma banda adulta ou de qualquer idade. Por isso, ele deve ser escolhido 
de forma diferenciada entre os garotos. Ele é um elemento central da banda, uma espécie de animador forte do grupo.

\section{CONSIDERAÇÕES FINAIS}

A experiência da parceria entre a Associação de Bandas de Congo (ABC-Serra) e o Poder Público, especialmente a Prefeitura Municipal da Serra, tem sido considerada pelos analistas como um exemplo a ser seguido pelos diversos municípios onde os mestres populares e outros agentes culturais têm buscado o mesmo sucesso. Dentre os inúmeros resultados positivos verificados ultimamente na Serra, como a aquisição dos recursos para fazer manutenção nos vestuários e nos instrumentos, ou mesmo a construção da Sede da ABC-Serra, que está sendo finalizada, é no trabalho com as crianças que está o maior orgulho da cidade. ${ }^{27}$ Nesse trabalho revela-se um esforço por manter a tradição viva entre as gerações em uma época na qual as mudanças sociais e econômicas decorrentes dos processos de globalização e metropolização têm trazido desafios para essas comunidades tradicionais.

Em geral, as autoridades estabeleceram no convênio que, ao receber os recursos financeiros, a $\mathrm{ABC}$-Serra daria como contrapartida um trabalho junto às crianças no sentido de formarem bandas de congo de crianças e jovens em suas comunidades tradicionais. $\mathrm{O}$ resultado entre esses jovens, muitas vezes ligados a uma cultura urbana, é de fazer frente ao enfraquecimento das tradições culturais, promovendo a proteção e a difusão do patrimônio material e imaterial das bandas de congo e de suas festas, no interior das comunidades tradicionais e da cidade em geral.

Os líderes do folclore se valeram de uma cultura já existente no local e de garotos que tinham alguma inserção espontânea na cultura das bandas de congo. Recorreram, ainda, a um cabedal de organização também já existente em algumas iniciativas que deram sentido à formação desse processo estruturado de transmissão cultural dos conhecimentos necessários para introduzir os jovens nessa cultura afro-capixaba-brasileira.

Há alguns avanços nessa estruturação, tais como: a fabricação de instrumentos de proporções menores, próprios para as crianças, que, com a fundação da Oficina de Instrumentos da ABC-Serra, foi dinamizada e facilitada; a estrutura organizativa dos coordenadores, que sempre fazem reuniões avaliativas; 
a organização dos encontros; a providência sobre transporte e alimentação, e ainda os belos vestuários dos meninos e meninas que tocam os instrumentos e das dançarinas, que utilizam vestidos longos para rodopiarem enquanto dançam carregando seus estandartes.

No entanto, pelo que temos observado até o momento, não foi regulamentado coletivamente um conjunto de estratégias e técnicas específicas para o desenvolvimento do projeto. A formação das bandas de congo mirins ficou sob a responsabilidade e sabedoria dos mestres e das comunidades. Cada uma criou estratégias próprias, o que fez gerar uma diversidade de resultados entre as comunidades.

$\mathrm{Na}$ parte técnica do aprendizado, há grande autonomia para os diversos coordenadores no sentido de trabalharem da forma que acharem melhor. Esse ponto final pode ser considerado positivo, mas certamente a troca de experiência entre os diversos coordenadores também pode trazer bons frutos.

\section{NOTAS}

${ }^{1}$ CARTA do Folclore Brasileiro. Folclore. Órgão Informativo da Comissão Espírito-Santense de Folclore, jul.-dez. 1951, p.25. Para uma discussão sobre os congressos e estratégias do movimento folclórico brasileiro ver VILHENA, Luís Rodolfo. Projeto e missão: o movimento folclórico brasileiro, 1947-1964. Rio de Janeiro: Funarte; Fundação Getúlio Vargas, 1997, especialmente cap. 4.

${ }^{2}$ RIBEIRO, Darcy. Estudos de Antropologia da Civilização. Teoria do Brasil. Livro I. 2.ed. Rio de Janeiro: Civilização Brasileira, 1975. p.139, grifos meus.

${ }^{3}$ SOUZA, João Francisco. A transmissão cultural. Sociopoética, ISSN 1980 7856, v.1, n.3, jan.-jul. 2009. Disponível em: eduep.uepb.edu.br/sociopoetica/publicacoes/vln3pdf/02_ joaofrancisco.pdf; Acesso em: 21 dez. 2011.

${ }^{4}$ DUSSEL, Inés. A transmissão cultural assediada: metamorfoses da cultura comum na escola. Trad. Neide Luzia de Rezende. Cadernos de Pesquisa, v.39, n.137, p.351-365, maio-ago. 2009. p.358. Disponível em: www.scielo.br/pdf/cp/v39n137/v39n137a02.pdf; Acesso em: 21 dez. 2011.

${ }^{5}$ BURKE, Peter. O que é história cultural? Trad. Sergio Goes de Paula. 2.ed. rev. e ampliada. Rio de Janeiro: Jorge Zahar, 2008. p.130. Peter Burke cita ainda que seria um processo de reconstrução, aquilo que Lévi-Strauss chamou de bricolage, e de Certeau, de reutilização.

${ }^{6}$ BANDA DE CONGO Amores da Lua. 50 anos. CD de áudio. Vitória (ES), 1999; NASCIMENTO, Adriano Roberto Afonso; MENANDRO, Paulo Rogério Meira. Canto de tambor e sereia: identidade e participação nas Bandas de Congo da Barra do Jucu. Vitória 
(ES): Edufes, 2002; BARROS, Paula Guedes. Banda de Congo da Barra do Jucu/ Estado do Espírito Santo. Folheto 4. Sub-Reitoria Comunitária/ Coordenação de Folclore. Vitória, 1983; MAZOCO, Eliomar Carlos. O congo de máscaras. Vitória: Edufes, 1990.

${ }^{7}$ A noção de 'área cultural' vem de Franz Boas, que a utiliza em seu método comparativo em Antropologia Cultural. Ela se refere a um território geográfico onde se manifestam traços culturais de uma determinada forma cultural específica. BOAS, Franz. Antropologia Cultural. Org., Apresentação e Trad. Celso Castro. 3.ed. Rio de Janeiro: Jorge Zahar, 2006.

${ }^{8}$ Alguns estudos se debruçaram sobre a história das bandas de congo. Sobre isso ver NEVES, Guilherme Santos. Bandas de Congos. Cadernos de Folclore. Rio de Janeiro: MEC/ Secretaria de Assuntos Culturais/Funarte, 1980, n.30; e COSTA, Michel Dal Col. As Bandas de Congo da Serra e seu ciclo folclórico e religioso: princípios de sua etnografia e história. Relatório de Pesquisa em poder do autor. Associação de Bandas de Congo da Serra (ABC-Serra), 2010.

${ }^{9}$ Há alguns anos, a Serra recebeu a visita de pesquisa de Carlos Stasi, estudioso na área musical, especialista em instrumentos de raspar, os chamados reco-recos, do Centro de Raspadores, sediado em Campinas (SP). Ele atestou em suas pesquisas pelo mundo a especificidade dos reco-recos capixabas, considerando-os únicos em sua forma. $\mathrm{O}$ folclorista capixaba Guilherme Santos Neves defendia a tese de esse instrumento ser uma contribuição indígena, e sobre isso ver NEVES, Guilherme Santos. Coletânea de estudos e registros do folclore capixaba. 1944-1982. 2v. Vitória: Centro Cultural de Estudos e Pesquisas do Espírito Santo, 2008, especialmente v.2, p.219-228.

${ }^{10}$ Para uma descrição detalhada dos instrumentos das bandas de congo do Espírito Santo, ver especialmente a Segunda Parte de LINS, Jaceguay. O Congo do Espírito Santo: uma panorâmica musicológica das bandas de congo. Vitória: s.n., 2009.

${ }^{11}$ Para se ter um contato direto com as toadas das bandas de congo ver os CDs das bandas de congo da Serra: BANDAS de Congo da Serra. O Canto da Alma - v.1 e 2. CD de áudio. Associação das Bandas de Congo da Serra - ABC-Serra. Serra, s.d.; BANDAS de Congo da Serra. O Canto da Alma - Homenagem ao Mestre Antônio Rosa. CD de áudio. Associação das Bandas de Congo da Serra - ABC-Serra. Serra, s.d. Para adquirir esses CDs e instrumentos próprios das bandas de congo entrar em contato com a ABC-Serra pelo telefone (27) 9961-5246. Ver ainda NEVES, 1980, e LINS, 2009, especialmente a terceira parte, onde o autor trata da melodia das músicas desses grupos.

${ }^{12}$ Recentemente, a ABC-Serra recebeu, das mãos do então presidente Luis Inácio Lula da Silva e do ministro da Cultura Gilberto Gil, a Comenda do Mérito Cultural, por grandes serviços prestados à cultura brasileira.

${ }^{13}$ Época em que foi fundada a Matriz e Paróquia de Nossa Senhora da Conceição da Serra, no Centro da Sede, onde até hoje se celebram missas e ocorre toda a vida da comunidade católica da região. É em frente a essa igreja que o Mastro de São Benedito é fincado todo ano.

${ }^{14}$ ANDRADE, Expedito. Entrevista concedida a Michel Dal Col Costa no Jardim Guanabara, Serra (ES), 2003. 
${ }^{15}$ Geralmente, em matas próximas à comunidade é colhida uma árvore chamada na região de 'guanandi', que é previamente trabalhada pelos festeiros até o ponto em que, como mastro simbólico, vai ser puxada em cortejo pelo itinerário tradicional do festejo. COSTA, Michel Dal Col. Cadernos de registro de observação de campo. Serra (ES), 2008-2011. (Mimeogr.).

${ }^{16}$ Tradição similar aos cavaleiros da Festa de São Benedito da Serra ocorre na cidade de Aparecida (São Paulo), em sua Festa de São Benedito. Lá eles também fincam um mastro em frente à Igreja de São Benedito, e o cortejo é acompanhado pelos 'Cavaleiros de São Benedito'. Na Serra, existe uma explicação para esse elemento: os cavaleiros representam os capatazes e senhores de escravos, que, no início, acompanhavam a festa dos escravos, para não terem surpresas. SILVA, Cristina Schmidt. Viva São Benedito! Festa popular e turismo religioso em tempo de globalização. Aparecida (SP): Ed. Santuário, 2000. Ver também COSTA, 2008-2011.

${ }^{17}$ HISTÓRICO da criação dos festejos de São Benedito da Serra e o primeiro congo criado pelos escravos. Documento da Associação das Bandas de Congo da Serra, atribuído a Antônio de Pádua Machado (Mestre Antônio Rosa). Arquivo da ABC-Serra. Serra, s.d. Ver ainda COSTA, Michel Dal Col. A explicação tradicional da Festa de São Benedito da Serra-ES e a proteção divina nos dramas no mar ao longo da história. Trabalho apresentado no XV Congresso Brasileiro de Folclore. São José dos Campos (SP), 2011.

${ }^{18}$ RODRIGUES, José (Mestre Chuchu) e BRANDES, Vladenira Corrêa de (Dona Nerinha). Entrevista. Entrevistador: Michel Dal Col Costa. Realizada na casa dos entrevistados, em Campinho da Serra, em 31 maio 2003.

${ }^{19}$ SACRAMENTO, Victor. Entrevista concedida a Michel Dal Col Costa, em 2 abr. 2008, na casa do entrevistado, na Serra Sede. O sr. Victor, nascido em 1932, faleceu há algum tempo, e de suas palavras é possível inferir que a sua participação na banda de congo infanto-juvenil precursora ocorreu quando ele tinha entre 11 e 26 anos, aproximadamente. Outro participante desse grupo foi o sr. Alberico Pereira da Penha, o Seu "Liliu". Esse antigo mestre me concedeu também uma entrevista e disse que participou desse grupo quando tinha 13 ou 14 anos. Nessa época, seu Victor, mais jovem, ainda não participava. PENHA, Alberico Pereira da (Liliu). Entrevista realizada em 23 abr. 2008 por Michel Dal Col Costa na casa do entrevistado, em Barcelona - Serra (ES).

${ }^{20}$ COSTA (2008-2011); e MIRANDA, José Carlos. Entrevista concedida ao autor, Serra (ES), 2011.

${ }^{21}$ Mestre Antônio Rosa, como é conhecido o falecido Antônio de Pádua Machado, foi um dos grandes líderes das bandas de congo e dos festejos folclóricos e religiosos da Serra e do Espírito Santo. Hoje recebe muitas homenagens, e uma delas está no museu e espaço de exposições Casa do Congo de Serra Sede, que recebeu seu nome. Para conhecer um pouco da história do Mestre Antônio Rosa, ver COSTA, Michel Dal Col. Mestre Antônio Rosa. Festeiro Serrano de Autoridade. Série Protagonistas da Serra. Jornal Tempo Novo, Serra (ES), 23-30 dez. 2011, ano 27, p.8. 
${ }^{22}$ CARVALHO, Fábio; DIAS, Alcione (Coord.) O congo na escola: elemento ressignificador de conhecimentos. Texto do projeto "Congo na Escola". Vitória (ES), depois de 1999 (ano de início do projeto). Arquivo pessoal; e BENTO, Vacinto do Rosário (Mestre Zé Bento). Entrevista concedida a Michel Dal Col Costa, realizada na casa do entrevistado, em Nova Almeida, em 27 jul. 2002.

${ }^{23}$ LEI no 2.288 da Prefeitura Municipal da Serra, Estado do Espírito Santo. Secretaria de Administração e Recursos Humanos. Publicada no Diário Oficial em 16 maio 2000. Vitória (ES); PIMENTEL, Teresinha Ozória Machado. Entrevista concedida a Michel Dal Col Costa, realizada na Sede da Associação das Bandas de Congo da Serra. Serra, 2000; "VERBA dá novo ânimo às Bandas de Congo da Serra". Jornal Tempo Novo, 13 maio 2003, p.4; CONVÊNIO no 014/2003-Setur; Processo n 087.1058/2002. Prefeitura Municipal da Serra, Estado do Espírito Santo. Publicado no Diário Oficial em 25 fev. 2003. Vitória, 2003. ${ }^{24}$ BANDA MIRIM de congo desfila neste domingo. Jornal Tempo Novo, 21 dez. 2001, Geral, p.27.

${ }^{25}$ VALDIRENE. (Rainha da Banda de Congo de Santiago). Banda de congo mirim de São Benedito de Santiago. Documento produzido na Casa do Congo Mestre Antônio Rosa. Serra, s.d.; HISTÓRICO da Banda de Congo Mirim União Jovens dos Reis Magos. Documento produzido na Casa do Congo Mestre Antônio Rosa. Documento avulso, s.n., s.d.; CONGO MIRIM Sant'Anna estreia hoje em Manguinhos. Jornal Tempo Novo, Serra (ES), 30 jun. 2001; BANDA DE CONGO Mirim São Benedito e Santo Antônio de Pádua. Documento produzido na Casa do Congo Mestre Antônio Rosa. Texto avulso, s.n., s.d.

${ }^{26}$ A HORA e a vez das crianças do congo. A Gazeta, Vitória, 17 maio 2002. Em Foco, p.4; TOCAR e cantar é mais que uma brincadeira. Notícia Agora, 26 ago. 2001, Cidade, p.7.

${ }^{27}$ É um cumprimento de uma das metas da ABC-Serra, como mostra o PROJETO SOCIAL Cultural de Revitalização das Bandas de Congo do Município da Serra (ES). Acervo ABC-Serra. Serra, s.d.

Artigo recebido em 8 de janeiro de 2012. Aprovado em 27 de março de 2012. 